\title{
UM OLHAR HUMANÍSTICO SOBRE A EDUCAÇÃO SUPERIOR BRASILEIRA
}

\author{
Suelânia Oliveira Araújo Miranda* \\ Maria Eugênia L. M. Castanho* \\ Vera Lúcia de Carvalho Machado*
}

\begin{abstract}
Resumo: $O$ texto discute as relações entre o trabalho e a educação no ensino superior brasileiro. Analisa as mudanças no perfil sócio-cultural dos trabalhadores de hoje e dos estudantes que ingressam no curso superior noturno procurando mostrar suas reais condições frente às conseqüências da globalização, suas dificuldades e seus caminhos na trajetória entre trabalho e estudo. Mostra que as causas podem ser encontradas no predomínio da formação técnica em detrimento de uma formação humanística de caráter global. Através de pesquisa bibliográfica estudam-se as contradições existentes na sociedade vendo que a educação precisa ser um direito e não uma mercadoria. Aponta ainda a necessidade de um trabalho didático-pedagógico voltado não só para a dimensão técnica, mas igualmente para as relações sociais com ênfase no professor universitário com consciência política e crítica. Conclui sobre a necessidade de compreender as transformações sociais, procurando na educação uma forma de construção do saber universitário com espaço para a articulação da qualidade com a quantidade, evitando a indesejável dicotomia entre ambos os aspectos.
\end{abstract}

Palavras-chave: Trabalho; Ensino Superior; Globalização; Formação Técnica; Formação Humanística.

\section{Introdução}

A observação da prática dos profissionais do ensino superior e da aprendizagem dos alunos que nele ingressam, principalmente em curso de graduação da área de

\footnotetext{
*Mestranda em Educação pela PUC-Campinas.

* Mestre e Doutora em Educação pela UNICAMP; Professora da PPGE (Programa de Pós-Graduação em Educação da PUC-Campinas; Bolsista Produtividade do CNPQ.

* Mestre pela PUC-Campinas, Doutora em Educação pela UNICAMP. Coordenadora e professora do Programa de Pós-Graduação em Educação da PUC-Campinas.
} 
Administração tem-nos chamado a atenção. Estes sujeitos passam pela aprendizagem, prioritariamente de conteúdos das matérias específicas e técnicas atendendo à necessidade primeira da sociedade capitalista visando à formação de uma massa ansiosa por algum título no ensino superior. Entendem que este é o caminho para a solução de problemas de ordem social e alcance de condições financeiras para a sua subsistência.

$\mathrm{O}$ foco principal desse entendimento está ligado ao currículo e à demanda do egresso visando ao atendimento de um mercado emergente, ligado à dimensão técnica. $\mathrm{O}$ professor é também um egresso desta exigência mercantilista, pois ali está, muitas vezes, pela necessidade de complementar sua renda familiar e julga estar preparado para o fazer pedagógico dada sua função empresarial durante o dia. É um técnico preparando outro técnico sem as devidas metodologias do ensino e da aprendizagem que assegurem a apreensão do conteúdo do currículo planejado e mais que isso, sem atentar para os demais aspectos da formação.

Sem esta compreensão o trabalho docente no Ensino Superior passa por um processo que afeta o domínio do conhecimento e as relações humanas estabelecidas na sociedade atual. É preciso promover discussões com vistas a se chegar a um novo trabalho pedagógico voltado a um currículo que dê espaço e importância para as articulações entre a experiência do trabalho e da educação superior.

\section{Profissionalização nas fábricas}

Acácia Kuenzer (1989) mostra que a heterogestão - fundamento taylorista - advém do racionalismo do século XVIII com os estudos de Adam Smith. A valorização do trabalho em detrimento do comércio artesão dá à burguesia e à Revolução Industrial subsídio para a elevação da produtividade e para a divisão do próprio trabalho. Justifica-se que esta divisão do trabalho nasce da desvalorização da mão de obra direta sobre o produto do início ao fim de sua confecção. Tem aceitação entre os trabalhadores frente à necessidade de subsistência humana, mas os deixa numa relação unilateral frente às decisões que permeiam sua nova condição de trabalhador, desqualificando suas habilidades na medida em que os afasta da elaboração total do produto e, com tudo isto, a educação, segundo a autora referenciada, sofre modificação em função deste novo método:

Embora a crescente racionalização dos campos do conhecimento nos séculos XVIII e XIX tivessem fornecido o pano de fundo para o emprego dos métodos racionais na execução e organização do trabalho, isto só foi possível com o surgimento de novas relações de produção, que determinaram o abandono violento do sistema artesanal pela introdução da máquina no processo produtivo. Ao mesmo tempo que revolucionou os métodos de organização do trabalho, a heterogestão trazida pelo novo modo de produção que se iniciava, o capitalista, revolucionou as formas de educação para o trabalho; à medida que a maquinaria substituiu o artesão, o aprendizado longo de um trabalho completo foi sendo substituído por um aprendizado cada vez mais fragmentado de uma tarefa parcial (KUENZER, 1989: 25).

$\mathrm{Na}$ sociedade de hoje, ainda prevalece a necessidade de subsistência e também a fragmentação das atividades desenvolvidas no mundo do trabalho. A venda da mão de obra do trabalhador está condicionada sempre à proposta apresentada pela empresa que o 
submete às suas condições de oferta. É ela quem determina as funções a serem desempenhadas e, conseqüentemente, o salário que será pago pelos préstimos oferecidos.

Kuenzer (1989) observa que o processo de qualificação só é oferecido aos níveis decisórios e técnicos, enquanto os níveis de execução acabam passando por um processo contrário, o de desqualificação. Isto se dá porque teoria e prática são apresentadas de forma dissociada. É no capitalismo que se justifica a busca incessante pela qualidade do produto durante a sua execução. O principal viés para se chegar nela é parcelar as etapas dessa execução colocando vários trabalhadores para dela participar. Fica claro que concepção e execução são atividades também dissociadas com valores e exigências diferenciadas também em tudo que é recurso voltado para o trabalhador. O valor atribuído a cada função desempenhada é valorado pelo empregador. Cada um receberá pela venda de sua mão de obra o que merecer, numa análise de cima para baixo hierarquicamente, dentro dos valores de quem planeja, não de quem executa. Estabelece-se assim que uns pensam e planejam, outros executam. É desta concepção de qualificação das atividades decisivas que jovens vão, geralmente por iniciativa própria, em busca de estudos no nível superior porque acreditam na idéia de ascensão social, de probabilidade de emprego e de rentabilidade maior. Para o exposto, elucida-se com a citação de Kuenzer:

No âmbito das prescrições acerca do controle do trabalho comprado tendo em vista os interesses do capitalismo, Taylor (1970) acresce à fragmentação do trabalho a divisão de funções entre gerência e trabalhador. Considerando a impossibilidade de que os trabalhadores independentes absorvam e executem processos uniformes e racionais de trabalho a fim de acompanhar o progresso tecnológico, a administração deverá responsabilizar-se pelo planejamento das tarefas a partir do conhecimento profundo do processo produtivo, cabendo ao operário apenas a execução segundo instruções superiores (1989:29-30).

$\mathrm{Na}$ maioria dos casos, estes jovens chegam ao ensino superior com uma renda per capita muito baixa. Exercendo uma função executiva de pouco prestígio, buscam aperfeiçoamento num curso superior que ofereça uma função que os qualifique. O tempo de conclusão dos estudos é fator importantíssimo. Imposto pela sociedade globalizada de um mercado ainda com visão tecnicista, a urgência prima pela conclusão rápida da aprendizagem dando mais importância a uma carga horária escolar reduzida em lugar de sua extensão e possibilidade de ampliação do conhecimento. Para eles, o egresso significa intelectualidade, capacidade para assumir funções executivas consideradas de prestígio social, que os insira no trabalho com uma renda maior e traga soluções para seus problemas de subsistência, conforme a análise de Castanho (2004:31).

A educação, nesse sentido, é fruto da divisão social do trabalho, que separa a produção material da produção intelectual, especializa os executores (da primeira) e os planejadores, dá poder a estes e o subtrai àqueles.

Pode-se comparar o mesmo perfil sócio-cultural desses jovens que buscam o trabalho e a aprendizagem, nas análises de Kuenzer e Castanho, exatamente com o mesmo comportamento dos candidatos ao ingresso no curso superior. Também o meio citado entre os autores é o mesmo vivenciado entre estes jovens: um mercado que instiga à concorrência sob pena de inutilidade social quando não se alcança o objetivo. Esse comportamento pode ter relação com a globalização. 
Não resta dúvida que a enorme quantidade de faculdades que surgem em São Paulo durante os anos noventa e a autorização de vagas na educação superior pelo MEC já são demonstrações de que são instituições que nascem pela expansão capitalista. O que se esperaria é que estas IES, bem como as políticas públicas tivessem preocupação com um currículo voltado para a formação técnica em consonância com a formação humanística de qualidade. Nesse sentido haveria necessidade de uma integração autônoma nos campos cultural, político, econômico e social brasileiros que promovesse a igualdade cultural e desencadeasse o mesmo nos outros campos de vivência humana. Assim, teríamos uma educação em nível superior preparada e voltada para a sociedade com formação humanística e fortalecida epistemologicamente.

\section{Das fábricas aos dias de hoje}

Antunes (2000) observa que é preciso levar em conta o perfil do empregador, a partir do século XX. Em lugar do fordismo, produção em série, taylorismo e suas inovações de idéias - neofordismo por exemplo - instalam-se outras concepções voltadas para a qualidade total e a exigência de controles de qualidade. Entram em cena, por exemplo, os chamados ISO - Internacional standard organization - Padrão internacional de organização que objetivam o alcance desta qualidade total. Tanto no comércio, quanto na indústria, a terceirização cresce principalmente no setor de serviços. Com tudo isso, o trabalhador também não tem relação direta com a empresa onde trabalha, pois se torna um prestador de serviços dela, contratado por outra. Neste tipo de contratação, a possibilidade de promoção do funcionário fica quase impossível. Se de um lado a empresa que recebe os serviços não tem a obrigação de promovê-lo, o funcionário também não recebe nenhum estímulo para isso. São duas partes dependentes, mas estranhas, trabalhando lado a lado. Cada vez mais, a fragmentação do trabalho junto ao produto é ainda maior, além das funções que são setorizadas e feitas etapa por etapa.

Antunes (id., ibidem: 49) referindo-se à mudança da classe operária industrial tradicional confirma o perfil sócio-cultural desses novos trabalhadores. Os candidatos ao ingresso no curso de ensino superior são jovens que chegam ao mercado de trabalho que exige técnica, aprendizado específico como forma de ascensão, mas a instabilidade social é o principal vilão e faz com que esses sujeitos se submetam às regras de um mercado que, exige, mas não cumpre com este perfil.

Observa-se, no universo do mundo do trabalho no capitalismo contemporâneo, uma múltipla processualidade: de um lado verificou-se uma desproletarização do trabalho industrial, fabril, nos países de capitalismo avançado, com maior ou menor repercussão em áreas industrializadas do Terceiro Mundo. Em outras palavras, houve uma diminuição da classe operária industrial tradicional. Mas, paralelamente, efetivou-se uma expressiva expansão do trabalho assalariado, a partir da enorme ampliação do assalariamento no setor de serviços; verificou-se uma significativa heterogeneização do trabalho, expressa também através da crescente incorporação do contingente feminino no mundo operário; vivencia-se também uma subproletarização intensificada, presente na expansão do trabalho parcial, temporário, precário, subcontratado, "tercerizado", que marca a sociedade dual no capitalismo avançado, da qual os gastarbeiterz na Alemanha e o lavoro nero na Itália são exemplos do enorme contingente de trabalho imigrante que se dirige para o chamado 
Primeiro Mundo, em busca do que ainda permanece no welfare state, invertendo o fluxo migratório de décadas anteriores, que era do centro para a periferia (Antunes, 2000:49).

Numa sociedade cada vez mais marcada pela globalização e pela concorrência, cada vez mais os trabalhadores são submetidos aos interesses do capitalismo. Aceitam reduções no tempo de estudos, submetem-se a condições de trabalho que desconsideram os valores humanos e visam o lucro do empregador, abdicam da convivência familiar ao se curvarem a uma jornada para o trabalho e outra para o estudo e desempenham atividades ou atuações fragmentadas sem a mínima identificação junto ao produto.

\section{Didática transformadora}

Com o mesmo poderio de desvalorização do trabalho, a fragmentação de idéias no espaço educativo também compromete a qualidade do aprendizado e, direciona o saber ao campo específico e, muitas vezes seletivo. É no planejamento que se integram os conhecimentos entre as disciplinas que compõem a estrutura curricular. Elas precisam, de fato, servir a um estudo solidário, de encadeamento de idéias teóricas e sólidas que visem à integração e não corram o risco da aprendizagem solitária, unicamente tecnicista em atendimento ao mercado de trabalho emergente. Cabe aos profissionais da educação uma visão humanística em relação ao que será aplicado como ciência em sala de aula, de forma que os estudantes tenham a condução de sua aprendizagem direcionada para a qualidade também das relações sociais em lugar da quantidade exigida por um mercado seletivo e exigente. Corroboram para isto os estudos de Rios:

A primeira demanda é a de superação da fragmentação - do conhecimento, da comunicação, das relações. Para isso, são necessárias uma visão de totalidade e uma articulação estreita de saberes e capacidades. Requer-se, então mais do que nunca, da Filosofia da Educação o olhar largo, abrangente, na intenção de ver o processo educativo em todos os aspectos sob os quais se apresenta e dos diversos pontos de vista em que se pode enfocá-lo (Rios, 2002:56).

Um dos caminhos apontados por Rios para a superação é a consciência dos educadores, muitos deles, frutos de uma pedagogia tecnicista totalmente vinculada ao racionalismo e ao tecnicismo. A mudança ocorrerá se a proposta vier acompanhada de consciência crítica sobre as relações sociais. Reside neste ponto, a necessidade da inserção de uma visão pedagógica em comunhão com a técnica voltada para o aprender que envolve o sentido, a apreensão e a reelaboração dos conteúdos. É preciso trabalhar com técnica, mas numa lógica dialética em que as várias dimensões da aprendizagem se encontrem e se complementem. É através desta consciência, que daremos o primeiro passo para mudar a ideologia dominante marcada pela globalização neoliberal, pelo vínculo ao afunilamento do mercado e, cada vez mais, pela fragmentação do que é ensinado em nossas escolas como mecanismo dominador com interesse voltado para o lucro.

O conhecimento pedagógico é necessário, pois o simples e puro conhecimento técnico, não é suficiente para trabalhar as diversas questões de ordem social voltadas para valores e atitudes que surgem numa sociedade em construção, para um homem em construção. Nesse sentido, a didática é transformadora na medida em que, pautada pelos estudos, pesquisas e preparação pedagógica, volta-se para a qualidade do desenvolvimento do ser humano em sociedade. 
O educador comprometido com a construção desta sociedade tem formas de abordagens voltadas para os desafios que os avanços tecnológicos pedem a cada momento, mas partem da dimensão humana para chegar à técnica. Sabendo que não há neutralidade no discurso, o trabalhador docente tem intencionalidade e reflexão em seus objetivos pedagógicos. Deve, então, despertar para o que está posto através de sua consciência crítica. O historiador Castanho, nos mostra que a escola é processo de mudança e espaço para o saber, portanto são os envolvidos nela que têm a possibilidade e a responsabilidade da transformação:

A escola foi o instrumento, ou o meio técnico, de que serviu a sociedade em mudanças, nos séculos XV e XVI, para a transmissão cultural. O processo, de maneira seminal retrocedeu ao século XII, assim como o capitalismo mercantil, já nesses tempos da Baixa Idade Média, dava seus primeiros passos. A história flui, não pula. As grandes mudanças demoram a ocorrer, como notou Marx e depois confirmou Braudel. A escolarização, lugar, técnica de ensinar, corpo de profissionais especializados no ensino, se é verdade que eclode no século XVI, com as escolas dos Irmãos da Vida Comum e, sobretudo, com os colégios e seminários jesuíticos, fez seus ensaios no século XII com as primeiras universidades, notadamente a de Paris (Castanho 2000). (...) Em termos instrumentais, surge a didática, saber e técnica da instrução. Especialmente, a escola surge como o lugar da instrução. Primeiramente como um lugar substituível, nem fixo nem muito especializado; mais tarde, como território apropriado especificamente para o ensino (Castanho, 2004:32).

Mas, nesta transformação precisamos levar em consideração o movimento histórico como fator de reflexão para o desenvolvimento da prática educativa que se pretende. Se para Castanho "a história flui, não pula", então para se chegar aos resultados pressupõe-se um processo. Nele, nossa consciência crítica apreende etapas atitudinais do homem com avanços e retrocessos que incorrem na busca decisiva da competência e da qualidade nas relações sociais e na aprendizagem. Passam por esse crivo os valores, as atitudes e as técnicas para transmissão do conhecimento, por parte do educador, daí, a necessidade de um discurso coerente e fundamentado técnica e politicamente para se chegar a ações transformadoras que levem à autonomia do saber.

Para Kuenzer (1989) a Pedagogia objetiva a educação do trabalhador, fazendo-o rever seus modos de ação no combate à dominação do capital frente à venda da força do trabalho. Somente quando compreendemos as relações sociais é que será possível adquirirmos autonomia sobre o fazer e neutralizamos as ideologias dominantes. Para ela, é imprescindível o desenvolvimento da consciência da classe trabalhadora. Para tanto, a hegemonia é uma relação pedagógica e deve ser entendida, como direção política, moral e cultural. Então, é preciso fazer um contraponto para conquistar uma autonomia que não nos deixe como objeto de manipulação.

A relação humana na docência é fator importante e fundamental. Não se trata de uma relação afetiva, romântica ou descompromissada da práxis reflexiva, mas do exercício da docência implicado em desenvolver um processo entre ensinar e aprender na dimensão humana. Assim também, nos mostra Kuenzer:

(...) Marx mostra que não é no indivíduo que se encontra a essência humana, mas nas relações sociais; ela se constrói com base nas relações do homem com a natureza, pelo trabalho, e com os outros homens. Essa essência humana que se 
manifesta nas relações sociais é a produção, que determina a existência da sociedade humana em seu conjunto, de cada indivíduo e da história... (1989: 34)

Não há sedimentação das relações humanas num processo de aprendizagem exclusivamente técnico. É através da base pedagógica que construímos opiniões e articulamos uma consciência política voltada para a formação humana. Os educadores precisam se voltar para uma formação que interfira na vida das pessoas de forma consciente e transformadora.

\section{Considerações finais}

Mesmo diante das mudanças ocorridas no perfil dos trabalhadores da sociedade atual, ainda prevalece a hegemonia da classe dirigente sobre os trabalhadores de formar a fazer valer ainda mais o poder do capital como ferramenta que leva ao lucro como objetivo essencial do empregador.

Desde a profissionalização das fábricas até hoje em que a contratação se dá mais nos campos do comércio e de serviços, a valorização da qualidade humana e das relações sociais parece não ter merecido enfoque ou qualquer atenção que se voltasse para a promoção dos cidadãos - trabalhadores e estudantes.

O produto desenvolvido - seu bem material - freqüentemente, cada vez mais se torna um produto alheio ao criador e sem autoria daqueles que o acabam. São tantos os feitores em etapas fragmentadas que não é possível atribuir a ninguém sua terminação, sua conclusão.

Como tudo isso é fruto de uma conjuntura econômica que busca a conclusão rápida para a obtenção do lucro com o menor custo, tem-se ações amparadas pela globalização que impõem a formação técnica como necessidade de preenchimento de vagas para o trabalho, que atendam a esse mercado emergente.

Desse valor dispensado às matérias técnicas ensinadas no ensino superior, em cursos de graduação, há uma demanda também técnica na seleção e escolha do professor universitário. Reside aí, o papel transformador do docente que deve buscar a valorização das relações humanas. Para que as instituições de Ensino Superior valorizem em seu P.P.P. (Projeto Político Pedagógico) a formação humanística, inclusive colocando em seus currículos disciplinas de cunho didático-pedagógico, precisamos da atuação de educadores que exerçam um papel político e crítico na exigência de valores conscientes e humanos.

O estudante não pode continuar sendo formado por um técnico e se transformar em mais um técnico sem perspectiva transformadora e tolhido por um currículo técnico que pode levar à massificação e à manipulação do saber. Os conhecimentos técnicos, políticos, morais e culturais precisam ser articulados e significados diante da realidade humana para que façam sentido, para que se voltem a uma visão crítica dentro de um processo dialético e de construção possibilitando competência, qualidade e autonomia humana. 


\title{
Bibliografia
}

ANTUNES, Ricardo. Adeus ao trabalho? Ensaio sobre as metamorfoses e a centralidade do mundo do trabalho. 7.ed. São Paulo: Cortez, 2000.

CASTANHO, Sérgio. Metodologia do Ensino ou da educação superior? Um olhar histórico. In: CASTANHO, Sérgio e CASTANHO, Maria Eugênia de L. M. (Orgs.) Temas e textos em metodologia do ensino superior. 3.ed. Campinas (SP): Papirus, 2004.

KUENZER, Acácia Z. Pedagogia da Fábrica. As relações de produção e a educação do trabalhador. 3.ed. São Paulo: Cortez, 1989.

LOPES, Antonia Osima. Aula Espositiva: superando o tradicional. In: VEIGA, Ilma P. Alencastro (Org.). Técnicas de ensino: por que não? 13.ed. Campinas (SP): Papirus, 2002.

RIOS, Terezinha Azeredo Rios. Compreender e ensinar. Por uma docência da melhor qualidade. 3.ed. São Paulo: Cortez, 2002.

SAVIANI, Dermeval. Pedagogia Histórico-Crítica. 10.ed. Campinas, SP: Autores Associados, 2008.

\begin{abstract}
The text discusses the relationship between work and education in Brazil's higher education. It analyzes the changes in the socio-cultural profile of today's workers and students who get into the university in the evening programs aiming at showing their real conditions in relation to the consequences of globalization, their difficulties and their paths through their struggling between work and studies. It shows that the causes can be found in the predominance of technical training at the expense of humanistic education of a global character. Through bibliographical search, which studies the contradictions in the society, we have an overview showing that education must be a right not a commodity. It points out the necessity of a pedagogical job that is educationally-oriented not just in the technical dimension, but also seeking social relations with emphasis in a university professor with political awareness and criticism capacity. It focuses on the need to comprehend the social transformations, seeking in education a form of building the knowledge acquired at the university with room for the articulation of quality along with quanity, avoiding the undesirable dichotomy between both aspects.
\end{abstract}

Key Words: Work; Higher Education; Globalization; Technical Formation; Humanistic Formation. 